\title{
Antithrombotic Therapy in Atrial Fibrillation - Evaluation and Positioning of New Oral Anticoagulant Agents -
}

Satoshi Ogawa, MD, PhD; Yukihiro Koretsune, MD, PhD; Masahiro Yasaka, MD, PhD; Yoshifusa Aizawa, MD, PhD; Hirotsugu Atarashi, MD, PhD; Hiroshi Inoue, MD, PhD; Shiro Kamakura, MD, PhD; Koichiro Kumagai, MD, PhD; Hideo Mitamura, MD, PhD; Ken Okumura, MD, PhD; Kaoru Sugi, MD, PhD; Takeshi Yamashita, MD, PhD

\begin{abstract}
Atrial fibrillation $(\mathrm{AF})$ is the most common cardiac rhythm disorder and a major risk factor for stroke. For more than 60 years, warfarin has been the only approved anticoagulant for prevention of stroke in patients with AF. Although highly effective, it has many limitations that make its use difficult. Therefore, several novel anticoagulants are under development to overcome the limitations of warfarin, and some of these have entered phase III clinical trials. Dabigatran is an oral, reversible direct thrombin inhibitor approved in Europe and in several other countries for the prevention of venous thromboembolism after elective knee and hip replacement surgery. It has also been approved in the United States and Japan for the prevention of stroke and systemic embolism in patients with nonvalvular AF. In this review, the mechanism of action and pharmacological properties of new anticoagulants are described in detail, and the correct use of dabigatran in clinical practice is discussed. (Circ $J$ 2011; 75: 15391547)
\end{abstract}

Key Words: Anticoagulation; Atrial fibrillation; Dabigatran; Stroke; Warfarin

A trial fibrillation (AF), the most common cardiac rhythm disorder and a major risk factor for stroke, exacts a high toll in morbidity and mortality and imposes an enormous economic burden. ${ }^{1}$ In the United States, AF is responsible for at least $15-20 \%$ of all strokes ${ }^{2}$ and AF independently increases the risk of ischemic stroke by 4- to 5-fold. ${ }^{2}$ In 2010, the estimated direct and indirect costs of stroke were US\$73.7 billion. ${ }^{2}$ The prevalence of AF increases significantly in the elderly, affecting an estimated $9-14 \%$ of the general population $>80$ years of age in North America and Western Europe. ${ }^{3,4}$ In Japan, the increase in the prevalence of $\mathrm{AF}$ in people aged over 70 years has been slower than in Western countries, with AF affecting only around $3 \%$ of the general population $>80$ years of age. ${ }^{4-6}$ Based on the medium variant estimates of the Population Projection for Japan, the absolute number of AF patients is estimated to be $>1$ million in the year $2030 .^{6}$
It is also important to consider that coagulation activity is increased in the left atrium of patients with paroxysmal AF during the non-paroxysmal period (ie, during sinus rhythm), ${ }^{7}$ something that was not previously recognized. ${ }^{7}$ Accordingly, these patients are at high risk of developing cerebral thromboembolism, even during sinus rhythm, and anticoagulation therapy may be more beneficial than antiplatelet therapy.

Vitamin K antagonists (VKA) were first introduced more than 60 years ago and until recently, they were the only orally active anticoagulants available for clinical use. ${ }^{8}$ Warfarin is the most widely used oral VKA for the long-term prophylaxis of thrombosis. Moreover, its use has increased as new clinical conditions capable of leading to thrombosis have been identified.

Warfarin reduces the risk of stroke in patients with nonvalvular AF by 68\%. ${ }^{9}$ Although highly effective, it has several limitations, including a narrow therapeutic window, ${ }^{9}$

Received March 17, 2011; revised manuscript received April 22, 2011; accepted April 25, 2011; released online June 9, 2011

Mita Hospital, International University of Health and Welfare, Tokyo (S.O.); Institute for Clinical Research, Osaka National Hospital, Osaka (Y.K.); Department of Cerebrovascular Medicine, National Hospital Organization, Kyushu Medical Center, Fukuoka (M.Y.); Niigata University Graduate School of Medical and Dental Science Cardiology, Niigata (Y.A.); Department of Internal Medicine and Cardiology, Nippon Medical School, Tama-Nagayama Hospital, Tokyo (H.A.); The Second Department of Internal Medicine, University of Toyama, Graduate School of Medicine, Toyama (H.I.); Division of Arrhythmia and Electrophysiology, Department of Cardiovascular Medicine, National Cerebral and Cardiovascular Center, Osaka (S.K.); Heart Rhythm Center, Fukuoka Sanno Hospital, Fukuoka (K.K.); Cardiovascular Department, Saiseikai Central Hospital, Tokyo (H.M.); Cardiology, Respiratory Medicine and Nephrology, Hirosaki University Graduate School of Medicine, Aomori (K.O.); Division of Cardiovascular Medicine, Toho University, Ohashi Hospital, Tokyo (K.S.); and The Cardiovascular Institute, Tokyo (T.Y.), Japan

Writing Group Members: S.O., Y.K., M.Y.

Writing Committee Members: Y.A., H.A., H.I., S.K., K.K., H.M., K.O., K.S., T.Y.

Mailing address: Satoshi Ogawa, MD, PhD, Mita Hospital, International University of Health and Welfare, 1-4-3 Mita, Minato-ku, Tokyo 108-8329, Japan. E-mail: sogawa@iuhw.ac.jp

ISSN-1346-9843 doi:10.1253/circj.CJ-11-0304

All rights are reserved to the Japanese Circulation Society. For permissions, please e-mail: cj@j-circ.or.jp 


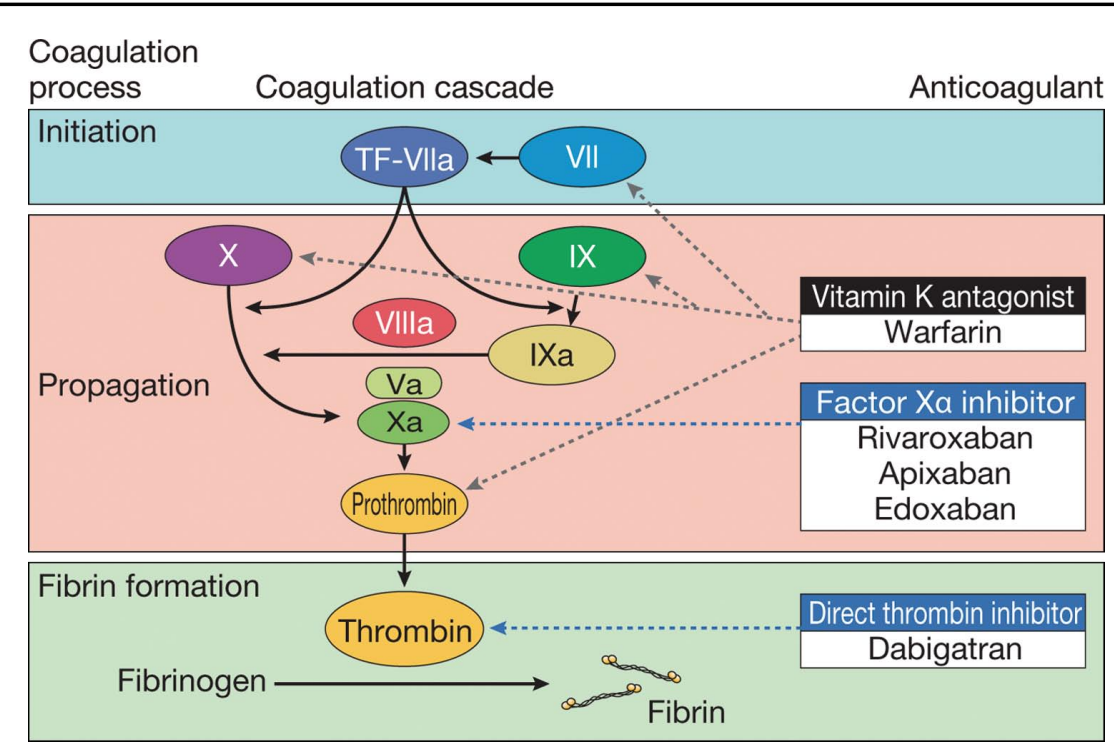

Figure 1. Site of action of anticoagulants in the coagulation cascade. ${ }^{14}$

increased risk of hemorrhage compared with control therapy, ${ }^{10}$ multiple food and drug interactions, and the need for frequent laboratory monitoring. ${ }^{11,12}$ As a result, the therapeutic range is achieved in less than two-thirds of patients in clinical practice, ${ }^{13}$ and only half of elderly patients with appropriate indications for VKAs are actually prescribed oral anticoagulants. ${ }^{14}$ Surprisingly, an analysis of the J-TRACE study revealed that, among patients with a $\mathrm{CHADS}_{2}$ score of 6 , the use of warfarin was actually lower in women than in men. ${ }^{15}$ Strategies to enhance the anticoagulant effect of warfarin have been evaluated but are limited for various reasons. For example, triple therapy comprising warfarin, aspirin and clopidogrel reduced the rate of major adverse cardiac and cerebral events compared with dual therapy comprising aspirin plus clopidogrel in patients with AF undergoing drug-eluting stent implantation. ${ }^{16}$ However, triple therapy was associated with an increased risk of overall bleeding. In another study, warfarin was administered with bucolome, a nonsteroidal antiinflammatory drug, which reduced the dose of warfarin required to maintain the international normalized ratio (INR) within an acceptable range. ${ }^{17}$ However, this approach did not affect the frequency of stroke or major bleeding.

These limitations have fueled efforts to develop new oral anticoagulants that are effective, safe, and convenient to use. A small number of novel anticoagulant agents (eg, oral direct thrombin inhibitors (DTIs) and factor Xa inhibitors) have reached phase III clinical trials for prevention of stroke and systemic embolism in patients with nonvalvular AF (NVAF). ${ }^{1,18}$ Dabigatran, a reversible DTI, has been approved in Europe and in several other countries for the prevention of venous thromboembolism after elective hip and knee replacement, and is in advanced clinical development for other thromboembolic diseases. ${ }^{19}$ In 2011 it was approved in Japan for the prevention of stroke and systemic embolism in patients with NVAF. This review will assess new oral anticoagulant agents for the prevention of stroke and systemic embolism in patients with NVAF, compare their stages of development, and address the properties, mechanisms of action, and proper clinical use of dabigatran specifically.

\section{Characteristics of New Anticoagulant Agents}

All anticoagulant agents inhibit thrombin activity by interrupting factors in the coagulation cascade, including a series of reactions that include amplification, fibrin formation, and the change from fibrinogen to fibrin (Figure 1). ${ }^{14}$ Both the intrinsic coagulation pathway (involving factors XII, XI, IX and VIII) and the extrinsic pathway (involving factor VII) end in the same common pathway, activation of factor $\mathrm{X}$ to factor Xa. ${ }^{1}$

Together with factor $\mathrm{Va}$, factor $\mathrm{Xa}$ forms the prothrombinase complex that activates prothrombin (factor II) to thrombin (factor IIa). ${ }^{1}$ Unlike indirect anticoagulants, such as heparins, which require antithrombin III to inhibit factor Xa or factor IIa, the novel orally available anticoagulants directly inhibit factor Xa or factor IIa. Thrombin not only activates fibrinogen into fibrin (factor 1a), but also activates factors V, VII, VIII, IX and XIII. Thus, blocking thrombin efficiently inhibits coagulation. ${ }^{1}$

The new oral anticoagulants have a rapid onset of action and can be given at fixed doses without routine coagulation monitoring; thus, they may simplify treatment paradigms and improve clinical outcomes. ${ }^{8}$ Factor Xa is a particularly attractive target for effective anticoagulation because it is positioned at the convergence point of the intrinsic and extrinsic coagulation pathways. Factor Xa catalyzes the conversion of prothrombin to thrombin-1 molecule of Factor Xa leads to the generation of $>1,000$ thrombin molecules. ${ }^{20}$

Direct factor Xa inhibitors block factor Xa and thus, indirectly, the generation of thrombin. Because direct inhibition of factor Xa does not affect the activity of existing thrombin, it may preserve hemostasis. In clinical terms, this might translate into efficacy with low bleeding risk. ${ }^{18}$ This conclusion requires further results of several ongoing clinical trials.

The other attractive target is direct inhibition of thrombin, the final mediator in the coagulation cascade that leads to the production of fibrin. ${ }^{20}$ Thrombin is a potent activator of platelets. ${ }^{8}$ In addition to inactivating free thrombin, DTIs are also able to inactivate fibrin-bound thrombin-an important trigger of thrombus expansion. ${ }^{21,22}$ Synthetic, small-molecule DTIs represent a new therapeutic class of antithrombotic 


\begin{tabular}{|c|c|c|c|c|}
\hline & Dabigatran & Rivaroxaban & Apixaban & Edoxaban \\
\hline Target factor & Thrombin & $\mathrm{Xa}$ & $\mathrm{Xa}$ & $\mathrm{Xa}$ \\
\hline $\mathrm{t}_{1 / 2}(\mathrm{~h})$ & $12-14$ & $9-13$ & $8-15$ & $6-11^{31}$ \\
\hline$t_{\max }(h)$ & $0.5-2$ & $2-4$ & $1-4$ & $1-1.5^{31}$ \\
\hline Bioavailability & $6.5 \%$ (humans) & $67-86 \%$ (animals) & $49 \%$ (humans) & $60 \%$ (animals) \\
\hline Protein binding & $35 \%$ & $92-95 \%$ & $87 \%$ & $40-59 \%$ \\
\hline Metabolism & Glucuronidation & CYP3A4/2J28 & CYP3A4 $4^{8}$ & CYPЗА \\
\hline Renal excretion & $80 \%$ & $33 \%$ & $25 \%$ & $35-39 \%$ \\
\hline Prodrug & Yes & No & No & No \\
\hline Company & $\begin{array}{l}\text { Boehringer } \\
\text { Ingelheim }\end{array}$ & $\begin{array}{c}\text { Bayer/ } \\
\text { Johnson \& Johnson }\end{array}$ & $\begin{array}{c}\text { Bristol-Myers Squibb/ } \\
\text { Pfizer }\end{array}$ & Daiichi Sankyo \\
\hline
\end{tabular}

\begin{tabular}{|c|c|c|c|c|c|}
\hline Target & Drug & Clinical trial & No. of patients/treatments & $\begin{array}{l}\text { CHADS }_{2} \\
\text { score }\end{array}$ & Study status \\
\hline Thrombin inhibitors & Dabigatran & RE-LY & $\begin{array}{l}n=18,113 / \text { Dabigatran } \\
\text { ( } 110 \text { or } 150 \mathrm{mg} \text { b.i.d.), Warfarin }\end{array}$ & $\geq 1$ & Published ${ }^{11,12}$ \\
\hline \multirow[t]{5}{*}{ Factor Xa inhibitors } & Rivaroxaban & ROCKET-AF & $\begin{array}{l}\mathrm{n}=14,264 / \text { Rivaroxaban } \\
(20 \mathrm{mg} \text { q.d.), Warfarin }\end{array}$ & $\geq 2$ & Completed ${ }^{35}$ \\
\hline & & J-ROCKET-AF & $\begin{array}{l}n=1,200 / \text { Rivaroxaban } \\
\text { (15 mg q.d.), Warfarin }\end{array}$ & $\geq 2$ & Completed \\
\hline & Apixaban & ARISTOTLE & $\begin{array}{l}n=18,206 / \text { Apixaban } \\
(5 \mathrm{mg} \text { b.i.d.), Warfarin }\end{array}$ & $\geq 1$ & Ongoing ${ }^{36}$ \\
\hline & & AVERROES & $\begin{array}{l}\mathrm{n}=5,599 / \text { Apixaban } \\
\text { (5 mg b.i.d.), Aspirin }\end{array}$ & $\geq 1$ & Published $^{37}$ \\
\hline & Edoxaban & ENGAGE-AF & $\begin{array}{l}n=20,500 / \text { Edoxaban } \\
\text { (30 or } 60 \mathrm{mg} \text { q.d.), Warfarin }\end{array}$ & $\geq 2$ & Ongoing \\
\hline
\end{tabular}

agents that may overcome the limitations of VKAs. ${ }^{23}$

Ximelagatran, a prodrug of the active metabolite melagatran, was the first oral agent in the new class of reversible DTIs. ${ }^{23,24}$ In an extensive phase III clinical program, it was evaluated for several indications, ${ }^{25,26}$ including the prevention and treatment of venous thromboembolism ${ }^{26-28}$ and the prevention of stroke in patients with AF. ${ }^{29,30}$ It was also approved in Europe for the prevention of venous thromboembolism after total hip or total knee replacement surgery, and has demonstrated potential for preventing thromboembolic events in patients with AF. However, it was subsequently withdrawn from the market because of hepatotoxicity. ${ }^{23}$ Nonetheless, the ximelagatran studies provided evidence that effective anticoagulation could be achieved with fixed-dose oral agents, without the need for frequent patient coagulation monitoring.

In addition to dabigatran, other new agents in the most advanced stages of clinical development for stroke prevention and $\mathrm{AF}$ include the direct factor $\mathrm{Xa}$ inhibitors rivaroxaban, apixaban and edoxaban. ${ }^{8}$ The characteristics of these drugs and the status of phase III trials are shown in Tables $\mathbf{1}$ and 2, respectively. Although rivaroxaban, apixaban and edoxaban all target factor Xa, their pharmacological characteristics differ widely. ${ }^{8,31}$ In terms of metabolism, all 3 drugs are metabolized by members of the cytochrome P450 family, suggesting that these drugs may be susceptible to drug or food interactions, although the clinical implications of this need to be formally evaluated.

By inhibiting factor Xa, rivaroxaban attenuates generation of thrombin from prothrombin and also inhibits factor-induced thrombin generation. ${ }^{32}$ As a consequence, prothrombin time increases with factor $\mathrm{Xa}$ inhibition in a dose-dependent manner. ${ }^{1}$ The half life of rivaroxaban is $7-11 \mathrm{~h}$. Rivaroxaban is largely excreted by the renal system; two-thirds of it is metabolized in the liver and one-third undergoes unchanged renal excretion. ${ }^{33}$

The ROCKET-AF (Randomized, Double-Blind Study Comparing Once Daily Rivaroxaban With Adjusted-Dose Oral Warfarin for the Prevention of Stroke in Subjects With Non-Valvular Atrial Fibrillation) study is the first phase III study comparing rivaroxaban with warfarin for prevention of stroke in patients with NVAF. ${ }^{34}$ Rivaroxaban showed noninferiority to warfarin but not superiority in high-risk patients (mean $\mathrm{CHADS}_{2}$ score: 3.5 ). Rates of bleeding on rivaroxaban were similar to those on warfarin. ${ }^{35}$

Apixaban is excreted via non-renal routes. The half-life of apixaban is $8-15 \mathrm{~h}$ and it has $49 \%$ bioavailability. A large phase III trial in patients with AF, the ARISTOTLE (Apixaban for the Prevention of Stroke in Subjects with Atrial Fibrillation trial) comparing the oral direct factor Xa drug to warfarin, is currently being conducted. Enrollment of 18,206 patients has been completed, and study results are expected in September 2011. ${ }^{36}$ The AVERROES trial (A Phase III Study of Apixaban in Patients with Atrial Fibrillation) compared apixaban with aspirin. ${ }^{37}$ The endpoint was a composite of stroke or systemic embolism in patients with AF unsuitable for VKAs. The study was halted prematurely because of superior efficacy of the study drug in reducing thromboembolic events. A total of 2,808 patients treated with apixaban showed a $55 \%$ reduction in stroke or systemic embolism without excessive risk of increased bleeding compared with aspirin. ${ }^{37}$

One of the newest oral direct factor Xa inhibitors, edoxaban, has a shorter half-life than the other drugs, but may also reach its maximal effect (ie, $t_{\max }$ ) more quickly, possibly 


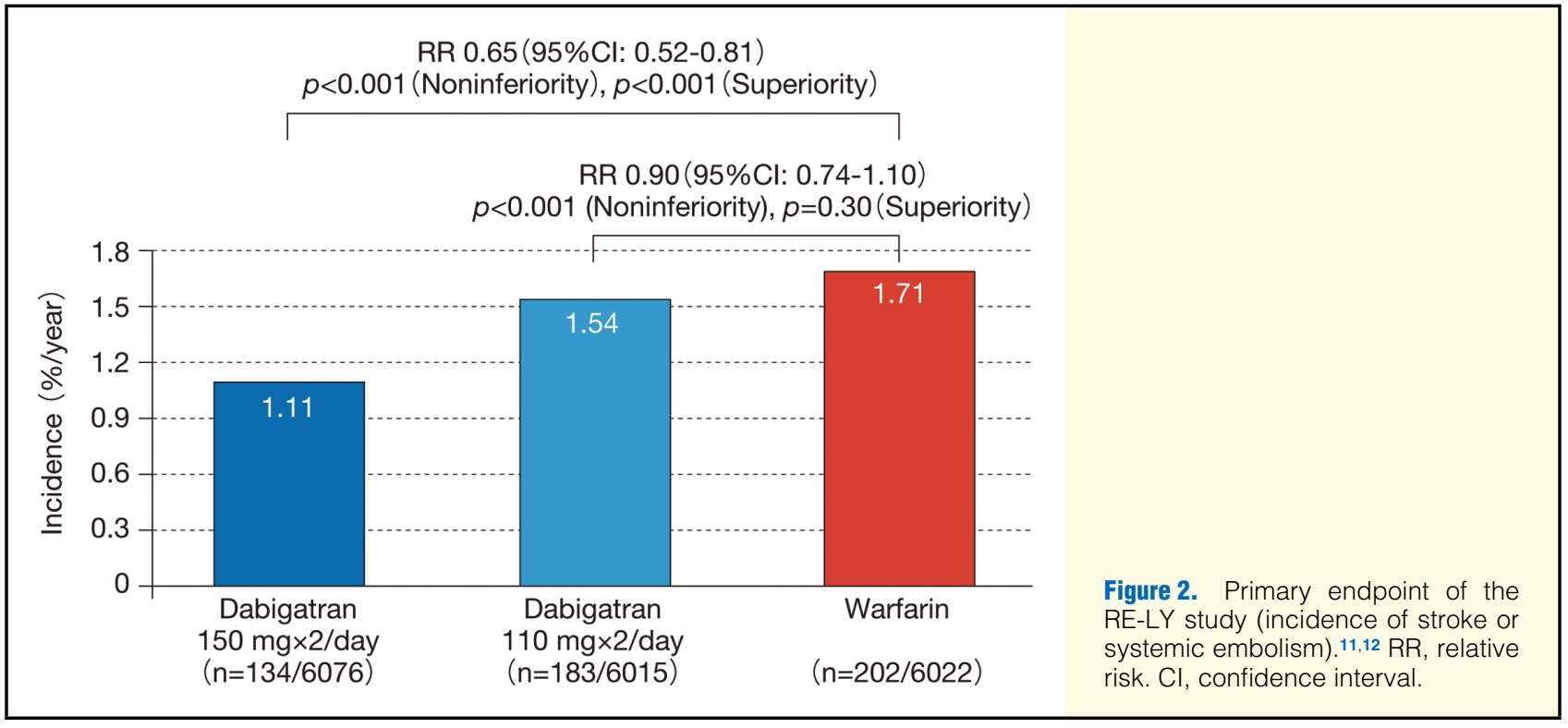

due to its lower protein binding. Like apixaban, it is excreted via non-renal routes. So far, one phase I trial has been published. ${ }^{31}$ A phase III study comparing its effects with those of warfarin in patients with AF is currently being performed (ENGAGE-AF-TIMI 48 trial [Global Study to Assess the Safety and Effectiveness of DU-176b vs. Standard Practice of Dosing With Warfarin in Patients With Atrial Fibrillation]: NCT00781391).

A recent trial of the DTI dabigatran has shown that the drug significantly reduces stroke risk in patients with AF compared with warfarin, with a better safety profile than warfarin. ${ }^{11,12}$ At the time of writing, dabigatran was the only novel anticoagulant to be approved in Japan. ${ }^{1}$ As summarized in Table 2, several large-scale studies have recently been completed or are ongoing for rivaroxaban, apixaban and edoxaban. In the absence of results from these studies and because these drugs have not yet received approval in Japan, we have focused this review on the data available for dabigatran. Our objective is to help inform physicians in Japan on the best use of this drug.

\section{Characteristics and Clinical Results of a New Anticoagulant Drug: Dabigatran Characteristics of Dabigatran}

Dabigatran etexilate is the prodrug of dabigatran, a nonpeptide direct thrombin (factor IIa) inhibitor ${ }^{9,23}$ (Figure 1). Following oral administration, dabigatran etexilate is rapidly hydrolyzed in vivo by serum esterase to its active form, dabigatran. ${ }^{38}$ It is absorbed through the gastrointestinal tract, reaching a peak plasma concentration $0.5-2 \mathrm{~h}$ after administration. ${ }^{9}$ It has a bi-exponential distribution phase, ${ }^{9}$ with a terminal half-life that ranges from 12 to $17 \mathrm{~h} .{ }^{39}$ Approximately $80 \%$ of the drug is excreted unchanged by the kidneys, with the remainder eliminated in bile. ${ }^{23,38}$

The absolute bioavailability of dabigatran is $6.5 \% .^{9,39} \mathrm{Be}-$ cause cytochrome $\mathrm{P} 450$ is not involved in the metabolism of the drug, and there is no induction or inhibition of cytochrome P450 enzyme activity, it has few drug interactions. ${ }^{1,38}$ Furthermore, limiting the intake of foods containing vitamin $\mathrm{K}$ is not required. ${ }^{39}$ The stable pharmacokinetics and pharma- codynamics of dabigatran allow fixed-dose administration without coagulation monitoring.

\section{Mechanisms of Action of Dabigatran}

Thrombin, a plasma serine protease, plays a central role in coagulation and hemostasis. Produced by the proteolytic cleavage of prothrombin, it catalyzes the conversion of fibrinogen to fibrin, leading to thrombus formation. ${ }^{23}$ By directly and specifically interacting with the active site of thrombin, univalent DTIs such as dabigatran inactivate fibrin-bound thrombin. ${ }^{40}$

Thrombin is also the most potent physiological agonist of platelet activation and aggregation. ${ }^{23}$ Dabigatran competitively inhibits human thrombin in a concentration-dependent manner, ${ }^{41}$ displaying highly selective and rapid but reversible binding to thrombin. Reversible binding may contribute to safer and more predictable anticoagulant treatment than has been observed with drugs that bind noncovalently and irreversibly. ${ }^{23}$

\section{Clinical Results of Dabigatran}

The efficacy and safety of dabigatran for preventing stroke or systemic embolism in patients with NVAF was evaluated in an international collaborative phase III clinical study (Randomized Evaluation of Long Term Anticoagulant Therapy: RE-LY) in which the drug was compared with dose-adjusted warfarin (INR: 2.0-3.0). ${ }^{9}$ The study has recently been completed. ${ }^{11,12}$ In this non-inferiority trial, 18,113 patients (including 326 Japanese patients) with AF and at least one risk factor for stroke were randomized to receive fixed doses of dabigatran [110 mg $(n=6,015)$ or $150 \mathrm{mg}$ b.i.d. $(\mathrm{n}=6,076)]$ or dose-adjusted warfarin $(n=6,022)$. The yearly rates of stroke or systemic embolism were $1.71 \%$ with warfarin, $1.54 \%$ with $110 \mathrm{mg}$ dabigatran b.i.d. ( $\mathrm{P}<0.001$ for non-inferiority) and $1.11 \%$ with $150 \mathrm{mg}$ dabigatran b.i.d. $(\mathrm{P}<0.001$ for non-inferiority; $\mathrm{P}<0.001$ for superiority); thus, $150 \mathrm{mg}$ dabigatran b.i.d. showed a significantly greater reduction in risk than warfarin (ie, superiority) (Figure 2). The rates of major bleeding, a primary safety outcome, were $3.57 \%$ per year with warfarin vs. $2.78 \%$ per year with $110 \mathrm{mg}$ dabigatran b.i.d. $(\mathrm{P}=0.003)$ and $3.32 \%$ per year with $150 \mathrm{mg}$ dabigatran b.i.d. $(\mathrm{P}=0.32)$ 

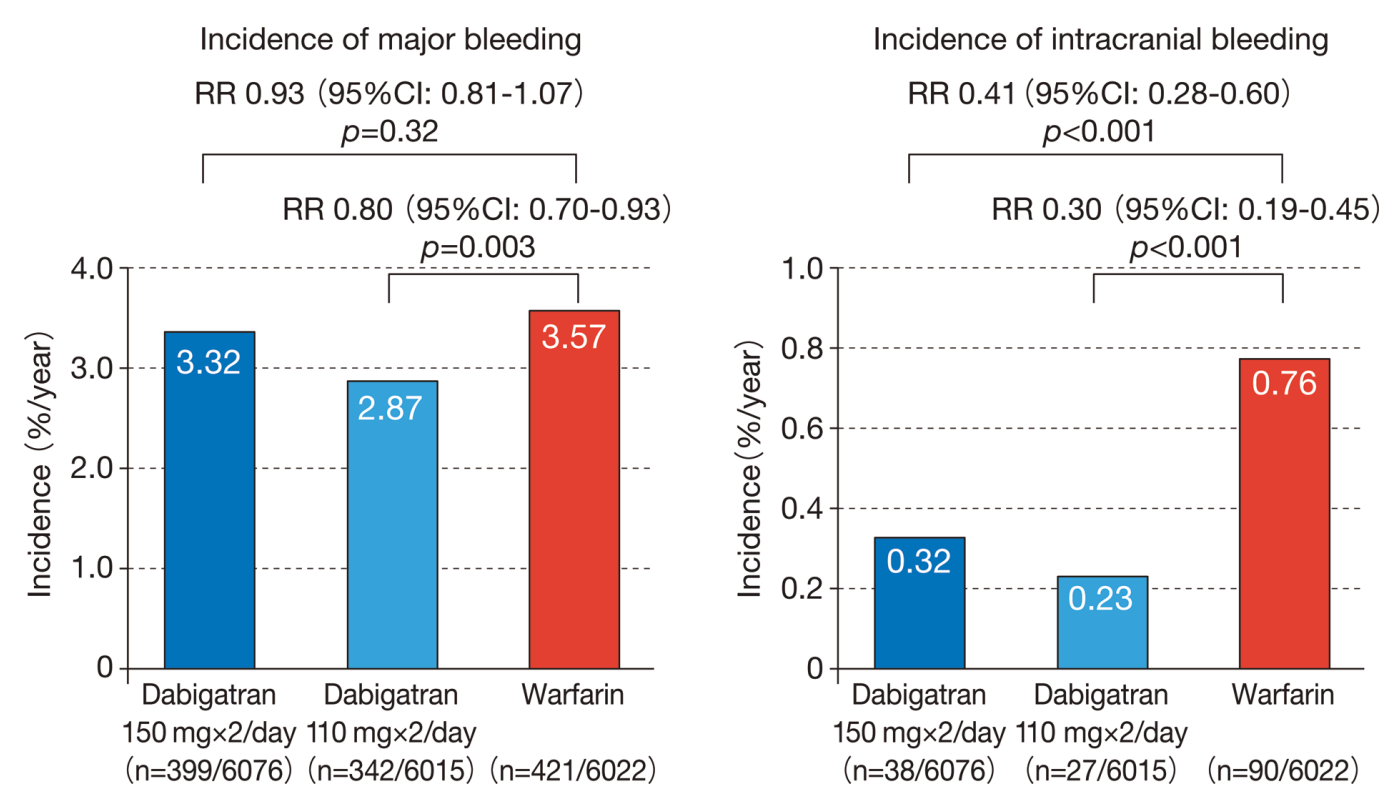

Figure 3. Incidence of major bleeding in the RE-LY study. ${ }^{11,12} \mathrm{RR}$, relative risk. Cl, confidence interval.

\section{Patients with NVAF}

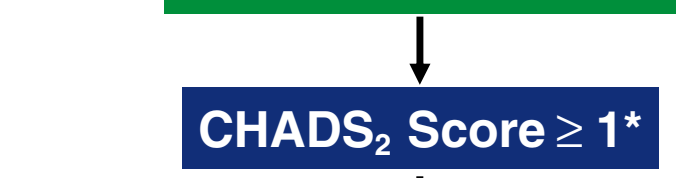

${ }^{*} \mathrm{CHADS}_{2}$ Score:

Congestive heart failure (1 point)

Hypertension (1 point)

75 years or older ( 1 point)

Diabetes mellitus (1 point)

Prior stroke/TIA (2 points)

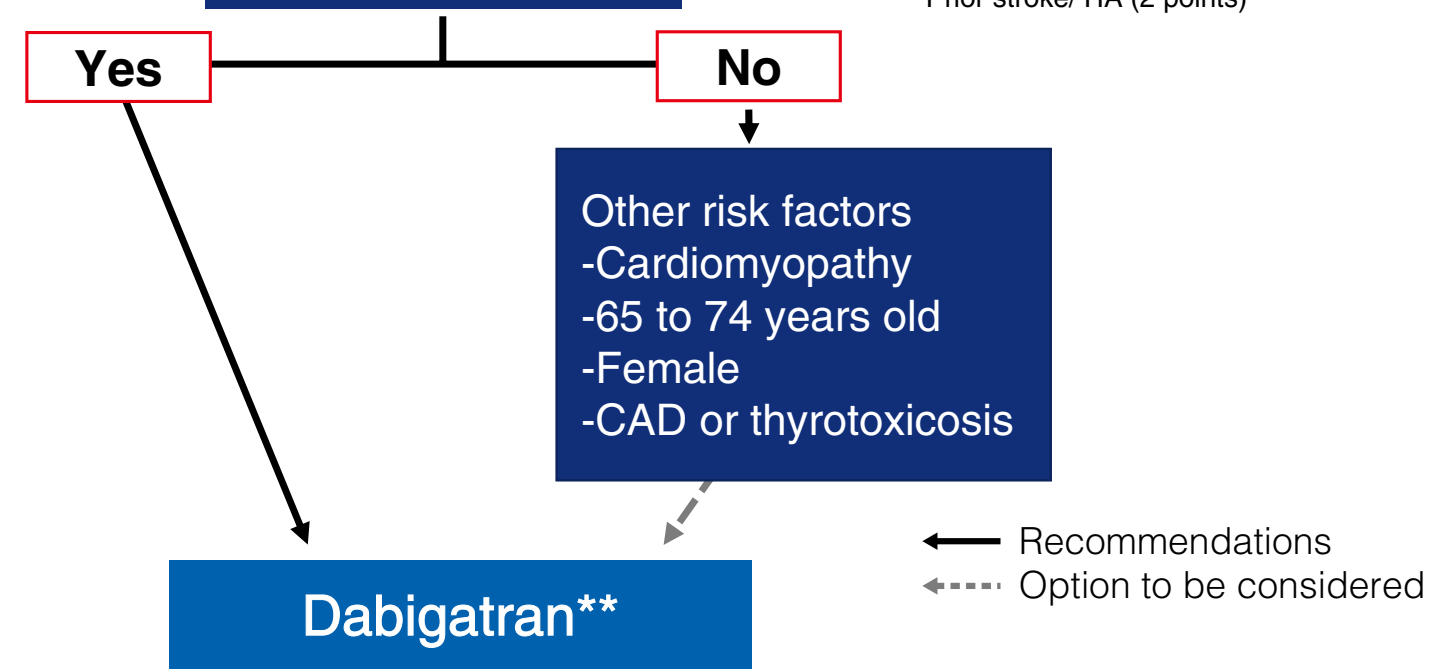

${ }^{\star \star}$ The recommended dose of dabigatran etexilate for adults is $150 \mathrm{mg}$ twice daily taken orally. The dose can be reduced to $110 \mathrm{mg}$ twice daily as needed.

For the following patients, a dose of $110 \mathrm{mg}$ twice daily can be considered -moderate renal impairment $(30-50 \mathrm{~mL} / \mathrm{min} \mathrm{CrCL})$ -concomitant use of P-glycoprotein inhibitor (oral) -70 years or older -history of gastrointestinal bleeding

Figure 4. Antithrombotic therapy for atrial fibrillation with dabigatran. 


\begin{tabular}{|c|c|c|c|}
\hline \multirow{2}{*}{ Renal function (Ccr, $\mathrm{ml} / \mathrm{min}$ ) } & \multirow[t]{2}{*}{ Half-life (h)* } & \multicolumn{2}{|c|}{$\begin{array}{l}\text { Timing of discontinuation after last dose } \\
\text { of dabigatran before surgery }\end{array}$} \\
\hline & & Standard risk of bleeding & High risk of bleeding ${ }^{\star \star}$ \\
\hline$>80$ & $13(11-22)$ & $24 \mathrm{~h}$ & $2-4$ days \\
\hline$>50$ to $\leq 80$ & $15(12-34)$ & $24 \mathrm{~h}$ & $2-4$ days \\
\hline$>30$ to $\leq 50$ & $18(13-23)$ & $\geq 48 \mathrm{~h}$ & 4 days \\
\hline$\leq 30^{\dagger}$ & $27(22-35)$ & $2-5$ days & $>5$ days \\
\hline
\end{tabular}

*Data from renal impairment study in healthy volunteers, geometric mean (range).

${ }^{\star \star}$ Types of surgery associated with a high risk of bleeding (or major surgery where complete hemostasis may be required) include but are not limited to cardiac surgery, neurosurgery, abdominal surgery or surgeries involving a major organ. Other procedures such as spinal anesthesia may also require complete hemostatic function. Other important determinants of bleeding risk include advancing age, comorbidities (eg, major cardiac, respiratory or liver disease) and concomitant use of antiplatelet therapy.

tDabigatran is contraindicated for use in these patients.

Ccr, creatinine clearance rate.

(Figure 3). The rates of intracranial bleeding were $0.76 \%$ per year with warfarin, $0.23 \%$ per year with $110 \mathrm{mg}$ dabigatran b.i.d. $(\mathrm{P}<0.001)$ and $0.32 \%$ per year with $150 \mathrm{mg}$ dabigatran b.i.d. $(\mathrm{P}<0.001)$ (Figure 3). ${ }^{11,12}$

Based on these results, $110 \mathrm{mg}$ dabigatran b.i.d. was associated with similar rates of stroke and systemic embolism and lower rates of major bleeding, and $150 \mathrm{mg}$ dabigatran b.i.d. was associated with lower rates of stroke and systemic embolism but similar rates of major bleeding, compared with warfarin. Furthermore, both doses of dabigatran were associated with significantly lower rates of intracranial bleeding. ${ }^{42}$ Overall, the RE-LY trial showed that dabigatran etexilate is a valid alternative to warfarin for oral anticoagulation in patients with $\mathrm{AF}$ and at risk of stroke. ${ }^{11,12}$

Patients in the RE-LY study had NVAF and at least one risk factor for stroke (previous stroke, transient ischemic attack or systemic embolism, left ventricular dysfunction, age $\geq 75$ years, or $\geq 65$ years with hypertension, coronary artery disease, or type 2 diabetes). Thus, the RE-LY findings in this population represent a significant breakthrough in anticoagulation management. ${ }^{43}$

\section{Correct Clinical Use of Dabigatran}

Dabigatran is a viable alternative to warfarin, offering greater efficacy, safety and convenience for many patients. ${ }^{43}$ The effective use of the drug requires that the risk of bleeding be reduced and prevention of stroke be maximized. Based on the results of the RE-LY study and on subanalyses from that study, ${ }^{11,12}$ appropriate therapeutic methods were evaluated for the use of the drug as anticoagulant therapy for AF patients. The RE-LY study included 5,775 patients $(31.9 \%)$ with a $\mathrm{CHADS}_{2}$ score of $0-1,{ }^{11}$ and consistent efficacy and safety profiles were observed in subgroups of patients with $\mathrm{CHADS}_{2}$ scores of $0-1,2$ and 3-6. ${ }^{44}$

Evidence-based data suggest that dabigatran is recommended for patients with NVAF and a CHADS 2 score $\geq 1$ (Figure 4) (Class I, Evidence level B). ${ }^{11,12,44}$ The optimal dosage and frequency of administration in adults seems to be $150 \mathrm{mg}(2 \times 75-\mathrm{mg}$ capsules $)$ b.i.d., which can be reduced to $110 \mathrm{mg}(1 \times 110-\mathrm{mg}$ capsule $)$ b.i.d. as needed. In patients with moderate renal dysfunction (creatinine clearance of 30$50 \mathrm{ml} / \mathrm{min}$ ), with concomitant use of P-glycoprotein inhibitors, aged $\geq 70$ years, and with history of gastrointestinal bleeding, $110 \mathrm{mg}$ dabigatran b.i.d. can be considered. For patients with a $\mathrm{CHADS}_{2}$ score $<1$ and other risk factors, including cardiomyopathy, age 65-74 years, female, coronary artery disease, or thyrointoxication, dabigatran is an option to be considered. ${ }^{11,12,44}$

Administration of Dabigatran During Cardioversion In the RE-LY study, dabigatran and warfarin were administered continuously during cardioversion. Data collected before, during and 30 days after cardioversion were analyzed. A total of 1,983 cardioversions were performed in 1,270 patients during the RE-LY study. Most cardioversions were electric, being performed in $85.6 \%, 81.9 \%$ and $83.3 \%$ of patients in the $110 \mathrm{mg}$ and $150 \mathrm{mg}$ dabigatran groups, and the warfarin group, respectively. ${ }^{45}$ The incidence of stroke or generalized embolism within 30 days of cardioversion was $0.77 \%$, $0.30 \%$ and $0.60 \%$, respectively. Major bleeding was infrequent in all groups. The RE-LY trial showed that dabigatran and warfarin offer similar efficacy in patients undergoing cardioversion. ${ }^{45}$

The Japanese guidelines for AF recommend that warfarin should be administered for 3 weeks before and 4 weeks after cardioversion in patients with AF lasting $\geq 48 \mathrm{~h}$ (or of unknown duration) to achieve an INR of 2.0-3.0 in patients $<70$ years old, or an INR of 1.6-2.6 in patients $\geq 70$ years old. ${ }^{4}$ A subgroup analysis of the RE-LY study revealed that the administration of dabigatran offers a safe alternative to warfarin for the prevention of stroke in AF patients undergoing cardioversion..$^{45}$ Thus, although warfarin is recommended in the current guidelines, ${ }^{4}$ dabigatran could be used instead, but with better safety (Class I, Evidence level B).

Tooth Extraction or Surgery Treatment with antithrombotic drugs should be continued during tooth extraction. ${ }^{4}$ Randomized controlled trials and observational studies have reported that tooth extraction can be safely performed in patients receiving antithrombotic drugs. ${ }^{46-49}$ It is generally considered that the same recommendation applies to dabigatran, although there is currently no evidence from patients undergoing tooth extraction.

Patients with therapeutic levels of dabigatran undergoing elective surgery or invasive procedures are at increased risk of bleeding; therefore, surgical interventions may require temporary discontinuation of dabigatran therapy. ${ }^{19}$ Depending on the degree of renal impairment and risk of bleeding, dabigatran should be stopped at least $24 \mathrm{~h}$ before elective surgery. ${ }^{19}$

In patients at higher risk of bleeding or in major surgery where complete hemostasis may be required, dabigatran should be stopped 2-4 days before surgery (Table 3$)^{19}$ and an alternative therapy, such as heparin, should be considered. The same criteria for discontinuing anticoagulant therapy before surgery were used in the RE-LY study. 
Once postoperative hemostasis is confirmed, the administration of dabigatran should be restarted as soon as clinically indicated. ${ }^{19}$ Because of its rapid onset, bridging to heparin at restart is generally unnecessary, unless oral administration is not feasible, in which case parenteral heparinization should be considered. ${ }^{19}$

Treatment of Bleeding Bleeding is the major adverse reaction of anticoagulant drugs and is associated with significant morbidity and long-term adverse outcomes, including increased rates of mortality. ${ }^{50-52}$ In the event of bleeding complications in patients receiving dabigatran, general emergency treatment should be conducted.

Dabigatran should be discontinued temporarily or permanently depending on the severity of hemorrhagic complications. The cause of bleeding should be confirmed and surgical hemostasis performed. Because dabigatran predominantly undergoes renal excretion, adequate diuresis should be maintained. Other supportive strategies to control severe bleeding include mechanical compression and transfusion of blood products (packed red cells or fresh frozen plasma, depending on associated anemia or coagulopathy), hemodialysis ${ }^{19,53}$ and high-volume hemofiltration. ${ }^{54}$ Within $2 \mathrm{~h}$ of oral administration, gastric lavage and adsorption to activated charcoal can be considered.

Recombinant activated factor VII (rFVIIa; NovoSeven ${ }^{\circledR}$, Novo Nordisk, Bagsvaerd, Denmark $)^{55}$ and prothrombin complex concentrates ${ }^{56}$ can also be useful to rapidly reverse coagulopathy. However, there are no published clinical data on the use of these agents in patients receiving dabigatran and information is limited for the other new oral anticoagulants. ${ }^{57}$ Therefore, their use in treating anticoagulant-associated bleeding is based on a combination of preclinical data, anecdotal case reports, and the absence of alternative therapies that might be effective. ${ }^{58}$

\section{Methods of Switching Between Anticoagulant Drugs}

Dabigatran is a viable alternative to warfarin, improving efficacy and safety in many respects for many patients. ${ }^{43}$ To switch from warfarin to dabigatran, the administration of warfarin should be discontinued until the INR is $<2.0 .{ }^{9}$ To switch from dabigatran to other injectable anticoagulant drugs, the change should be made $12 \mathrm{~h}$ after the administration of dabigatran. To transfer patients from other injectable anticoagulant drugs to dabigatran, dabigatran should be administered $2 \mathrm{~h}$ before the next dose or at the time of discontinuation in the case of continuous intravenous injection.

\section{Future Scenarios for Antithrombotic Therapy for AF}

Anticoagulation remains the cornerstone for the prevention and treatment of thromboembolic disorders, which are among the major causes of morbidity and mortality. ${ }^{8}$ Well-established agents, although effective, have significant limitations. ${ }^{8}$ Warfarin reduces the risk of stroke in patients with $\mathrm{AF}$, but increases the risk of hemorrhage and is difficult to use. ${ }^{11,12}$

The new oral anticoagulants may provide better alternatives to warfarin for stroke prevention in patients with $\mathrm{AF}$ because they do not require routine coagulation monitoring or dose adjustment. They are administered orally at fixed doses, have a rapid onset of action, predictable pharmacokinetics and pharmacodynamics, and minimal food-drug or drugdrug interactions. ${ }^{8}$ Adopting the novel oral agents will considerably simplify the therapeutic strategy. In the acute treatment phase, an oral regimen will be sufficient for the whole treatment duration, without the need for bridging therapy from a parenteral anticoagulant. ${ }^{8}$ A single-drug therapy would provide convenience both within and outside the hospital setting. Indeed, the introduction of new oral anticoagulants may reduce the length of hospital stay, facilitating discharge, particularly in patients who cannot or are unwilling to carry out subcutaneous injection themselves.

Clinical studies have established the non-inferiority, or even superiority, of several regimens of the new oral agents compared with conventional therapy. ${ }^{8}$ In the RE-LY trial, for example, the rate of intracranial bleeding among patients treated with dabigatran was less than one-third of that among patients treated with warfarin, without a reduction in the efficacy against stroke. The benefit of dabigatran may be explained in part by the twice-daily dosing regimen. Because dabigatran has a half-life of 12-17 h, twice-daily dosing reduces the variability in the anticoagulation effect, especially compared with that of warfarin, which is difficult to control. Warfarin inhibits several components of the coagulation pathway, including factors II, VII, IX and X, and proteins C and $\mathrm{S}$. In contrast, dabigatran selectively inhibits thrombin, and may have antithrombotic efficacy while preserving some of the other hemostatic mechanisms in the coagulation system. In this way, it might mitigate the risk of bleeding such as intracranial hemorrhage. ${ }^{11}$

Many physicians have concerns about administering warfarin, because it has a narrow therapeutic window and requires routine coagulation monitoring and dose adjustment. ${ }^{8} \mathrm{~A}$ metaanalysis showed that in community-based practice in the United States, patients with AF who received warfarin spent only $51 \%$ of their time within the therapeutic INR of 2.0$3.0,{ }^{59}$ leaving them at risk of either thromboembolism or bleeding complications.

Dabigatran (a DTI) could replace warfarin in this indication, especially because of its superior efficacy and better safety profile. ${ }^{8}$ The RE-LY trial confirmed that the former is a valid alternative to conventional therapy in patients with NVAF at risk of stroke. ${ }^{43}$ After a decade of failures, these findings signify a breakthrough in anticoagulation management. ${ }^{43}$

However, novel anticoagulant agents have potential limitations. Of particular concern is that there are no antidotes to any of the novel oral agents with anticoagulant activity. Accordingly, clinicians must be aware of the risk of potentially severe hemorrhage, particularly in patients undergoing surgery. However, the lack of specific antidotes (in case immediate reversal is needed) is a theoretical rather than a practical liability for the newer agents because their half-lives are relatively short compared with that of warfarin, meaning the risk of severe hemorrhage is much reduced. ${ }^{8}$

Dabigatran has been approved in the United States and in Japan for the prevention of stroke and systemic embolism in patients with NVAF. Studies on the use of dabigatran in tooth extraction have yet to be conducted. Meanwhile, phase III clinical trials for the factor Xa inhibitors have only recently been or are yet to be completed or published. Despite their known benefits, physicians in general practice are often unwilling to adopt new therapies, and it may take many years for findings from such studies as RE-LY to filter down to routine clinical care. For this reason, it is important for specialists to promote knowledge about dabigatran and advocate its widespread use. To ensure patient safety, however, it is equally vital to educate physicians about guidelines on its appropriate administration. In these ways, we can make it easier for physicians to prescribe effective levels of anticoagulation and easier for patients to comply with treatment plans. 


\section{References}

1. Schirmer SH, Baumhäkel M, Neuberger HR, Hohnloser SH, van Gelder IC, Lip GY, et al. Novel anticoagulants for stroke prevention in atrial fibrillation: Current clinical evidence and future developments. J Am Coll Cardiol 2010; 56: 2067-2076.

2. Writing Group Members, Lloyd-Jones D, Adams RJ, Brown TM, Carnethon M, Dai S, et al. Heart disease and stroke statistics-2010 update: A report from the American Heart Association. Circulation 2010; 121: e46-e 215.

3. Feinberg WM, Blackshear JL, Laupacis A, Kronmal R, Hart RG. Prevalence, age distribution, and gender of patients with atrial fibrillation: Analysis and implications. Arch Intern Med 1995; 155: 469473.

4. JCS Joint Working Group. Guidelines for pharmacotherapy of atrial fibrillation (JCS 2008): Digest version. Circ J 2010; 74: 24792500.

5. Ohsawa M, Okayama A, Sakata K, Kato K, Itai K, Onoda T, et al. Rapid increase in estimated number of persons with atrial fibrillation in Japan: An analysis from national surveys on cardiovascular diseases in 1980, 1990 and 2000. J Epidemiol 2005; 15: 194-196.

6. Inoue H, Fujiki A, Origasa H, Ogawa S, Okumura K, Kubota I, et al. Prevalence of atrial fibrillation in the general population of Japan: An analysis based on periodic health examination. Int J Cardiol 2009; 137: 102-107.

7. Koretsune Y. The incidence of ischemic stroke: Paroxysmal AF vs persistent/permanent AF. Circ J 2009; 73: 1393-1394.

8. Mavrakanas T, Bounameaux H. The potential role of new oral anticoagulants in the prevention and treatment of thromboembolism. Pharmacol Ther 2011; 130: 46-58.

9. Ezekowitz MD, Connolly S, Parekh A, Reilly PA, Varrone J, Wang S, et al. Rationale and design of RE-LY: Randomized evaluation of long-term anticoagulant therapy, warfarin, compared with dabigatran. Am Heart J 2009; 157: 805-810, 810.e801-e802.

10. Hart RG, Pearce LA, Aguilar MI. Meta-analysis: Antithrombotic therapy to prevent stroke in patients who have nonvalvular atrial fibrillation. Ann Intern Med 2007; 146: 857-867.

11. Connolly SJ, Ezekowitz MD, Yusuf S, Eikelboom J, Oldgren J, Parekh A, et al. Dabigatran versus warfarin in patients with atrial fibrillation. N Engl J Med 2009; 361: 1139-1151.

12. Connolly SJ, Ezekowitz MD, Yusuf S, Reilly PA, Wallentin L; Randomized Evaluation of Long-Term Anticoagulation Therapy Investigators. Newly identified events in the RE-LY trial. $N$ Engl J Med 2010; 363: 1875-1876.

13. Matchar DB, Samsa GP, Cohen SJ, Oddone EZ, Jurgelski AE. Improving the quality of anticoagulation of patients with atrial fibrillation in managed care organizations: Results of the managing anticoagulation services trial. Am J Med 2002; 113: 42-51.

14. Umer Usman MH, Raza S, Raza S, Ezekowitz M. Advancement in antithrombotics for stroke prevention in atrial fibrillation. J Interv Card Electrophysiol 2008; 22: 129-137.

15. Inoue $H$, Nozawa $T$, Hirai $T$, Goto $S$, Origasa $H$, Shimada $K$, et al. Sex-related differences in the risk factor profile and medications of patients with atrial fibrillation recruited in J-TRACE. Circ J 2010; 74: $650-654$

16. Gao F, Zhou YJ, Wang ZJ, Shen H, Liu XL, Nie B, et al. Comparison of different antithrombotic regimens for patients with atrial fibrillation undergoing drug-eluting stent implantation. Circ J 2010; 74: 701-708.

17. Obata H, Watanabe H, Ito M, Hirono S, Hanawa H, Kodama M, et al. Effects of combination therapy with warfarin and bucolome for anticoagulation in patients with atrial fibrillation. Circ J 2010; 75: 201-203.

18. Kubitza D, Haas S. Novel factor Xa inhibitors for prevention and treatment of thromboembolic diseases. Expert Opin Invest Drugs 2006; 15: 843-855.

19. van Ryn J, Stangier J, Haertter S, Liesenfeld KH, Wienen W, Feuring M, et al. Dabigatran etexilate--a novel, reversible, oral direct thrombin inhibitor: Interpretation of coagulation assays and reversal of anticoagulant activity. Thromb Haemost 2010; 103: $1116-1127$.

20. Mann KG. The biochemistry of coagulation. Clin Lab Med 1984; 4: $207-220$.

21. Kumar R, Béguin S, Hemker HC. The effect of fibrin clots and clot-bound thrombin on the development of platelet procoagulant activity. Thromb Haemost 1995; 74: 962-968.

22. Weitz JI. New oral anticoagulants in development. Thromb Haemost 2010; 103: $62-70$.

23. Stangier J. Clinical pharmacokinetics and pharmacodynamics of the oral direct thrombin inhibitor dabigatran etexilate. Clin Pharmaco- kinet 2008; 47: 285-295.

24. Weitz JI, Bates SM. New anticoagulants. J Thromb Haemost 2005; 3: $1843-1853$.

25. Testa L, Andreotti F, Biondi Zoccai GG, Burzotta F, Bellocci F, Crea F. Ximelagatran/melagatran against conventional anticoagulation: A meta-analysis based on 22,639 patients. Int J Cardiol 2007; 122: $117-124$.

26. Francis CW, Berkowitz SD, Comp PC, Lieberman JR, Ginsberg JS, Paiement G, et al. Comparison of ximelagatran with warfarin for the prevention of venous thromboembolism after total knee replacement. N Engl J Med 2003; 349: 1703-1712.

27. Schulman S, Wåhlander K, Lundström T, Clason SB, Eriksson H, THRIVE III Investigators. Secondary prevention of venous thromboembolism with the oral direct thrombin inhibitor ximelagatran. N Engl J Med 2003; 349: 1713-1721.

28. Fiessinger JN, Huisman MV, Davidson BL, Bounameaux H, Francis $\mathrm{CW}$, Eriksson $\mathrm{H}$, et al. Ximelagatran vs low-molecular-weight heparin and warfarin for the treatment of deep vein thrombosis: A randomized trial. JAMA 2005; 293: 681-689.

29. Olsson SB, Executive Steering Committee of the SPORTIF III Investigators. Stroke prevention with the oral direct thrombin inhibitor ximelagatran compared with warfarin in patients with non-valvular atrial fibrillation (SPORTIF III): Randomised controlled trial. Lancet 2003; 362: 1691-1698.

30. Albers GW, Diener HC, Frison L, Grind M, Nevinson M, Partridge $\mathrm{S}$, et al. Ximelagatran vs warfarin for stroke prevention in patients with nonvalvular atrial fibrillation: A randomized trial. JAMA 2005; 293: 690-698.

31. Ogata K, Mendell-Harary J, Tachibana M, Masumoto H, Oguma T, Kojima M, et al. Clinical safety, tolerability, pharmacokinetics, and pharmacodynamics of the novel factor Xa inhibitor edoxaban in healthy volunteers. J Clin Pharmacol 2010; 50: 743-753.

32. Gerotziafas GT, Elalamy I, Depasse F, Perzborn E, Samama MM. In vitro inhibition of thrombin generation, after tissue factor pathway activation, by the oral, direct factor Xa inhibitor rivaroxaban. J Thromb Haemost 2007; 5: 886-888.

33. Kubitza D, Becka M, Mueck W, Zuehlsdorf M. Safety, tolerability, pharmacodynamics, and pharmacokinetics of rivaroxaban [an oral, direct factor Xa inhibitor] are not affected by aspirin. J Clin Pharmacol 2006; 46: 981-990.

34. ROCKET AF Study Investigators. Rivaroxaban-once daily, oral, direct factor Xa inhibition compared with vitamin $\mathrm{K}$ antagonism for prevention of stroke and embolism trial in atrial fibrillation: Rationale and design of the ROCKET AF study. Am Heart J 2010; 159: $340-347$, e341.

35. Patel MR, ROCKET AF Executive Steering Committee. Stroke prevention using the oral direct factor Xa inhibitor rivaroxaban compared with warfarin in patients with nonvalvular atrial fibrillation (ROCKET AF). Circulation 2010; 122: 2215-2226 (abstract 21839).

36. Lopes RD, Alexander JH, Al-Khatib SM, Ansell J, Diaz R, Easton $\mathrm{JD}$, et al. Apixaban for reduction in stroke and other thromboembolic events in atrial fibrillation (ARISTOTLE) trial: Design and rationale. Am Heart J 2010; 159: 331-339.

37. Connolly SJ, Eikelboom J, Joyner C, Diener HC, Hart R, Golitsyn $\mathrm{S}$, et al. Apixaban in patients with atrial fibrillation. $N$ Engl J Med 2011; 364: 806-817.

38. Blech S, Ebner T, Ludwig-Schwellinger E, Stangier J, Roth W. The metabolism and disposition of the oral direct thrombin inhibitor, dabigatran, in humans. Drug Metab Dispos 2008; 36: 386-399.

39. Stangier J, Rathgen K, Stähle H, Gansser D, Roth W. The pharmacokinetics, pharmacodynamics and tolerability of dabigatran etexilate, a new oral direct thrombin inhibitor, in healthy male subjects. Br J Clin Pharmacol 2007; 64: 292-303.

40. Hauptmann J, Stürzebecher J. Synthetic inhibitors of thrombin and factor Xa: From bench to bedside. Thromb Res 1999; 93: 203-241.

41. Wienen W, Stassen JM, Priepke H, Ries UJ, Hauel N. In-vitro profile and ex-vivo anticoagulant activity of the direct thrombin inhibitor dabigatran and its orally active prodrug, dabigatran etexilate. Thromb Haemost 2007; 98: 155-162.

42. Gage BF. Can we rely on RE-LY? N Engl J Med 2009; 361: 12001202.

43. Heidbuchel H, Verhamme P. Dabigatran for stroke prevention in atrial fibrillation: From RE-LY to daily clinical practice. Acta Cardiol 2010; 65: 491-497.

44. Oldgren J, Alings M, Darius H, Eikelboom J, Ezekowitz M, Parekh A, et al, editors. Dabigatran versus warfarin in atrial fibrillation patients with low, moderate, and high CHADS2 Score: A RE-LY subgroup analysis. In: Proceedings of ACC10, March 14-16, 2010. Atlanta: American College of Cardiology. 
45. Nagarakanti R, Ezekowitz MD, Oldgren J, Yang S, Chernick M, Aikens TH, et al. Dabigatran versus warfarin in patients with atrial fibrillation: An analysis of patients undergoing cardioversion. Circulation 2011; 123: 131-136.

46. Evans IL, Sayers MS, Gibbons AJ, Price G, Snooks H, Sugar AW. Can warfarin be continued during dental extraction? Results of a randomized controlled trial. Br J Oral Maxillofac Surg 2002; 40: $248-252$.

47. Ardekian L, Gaspar R, Peled M, Brener B, Laufer D. Does lowdose aspirin therapy complicate oral surgical procedures? $\mathrm{J} \mathrm{Am}$ Dent Assoc 2000; 13: 331-335.

48. Morimoto Y, Niwa H, Yoneda T, Kimura K, Yasaka M, Minematsu K. Hemostatic management of tooth extraction in patients undergoing antithrombotic therapy. J Jpn Stomatol Soc 2004; 53: 74-80 (in Japanese).

49. Makiura N, Yasaka M, Minematsu K. Management of hemorrhagic complications at dental extraction in patients treated with warfarin Jpn J Stroke 2005; 27: 424-427 (in Japanese).

50. Rao SV, O'Grady K, Pieper KS, Granger CB, Newby LK, Van de Werf $\mathrm{F}$, et al. Impact of bleeding severity on clinical outcomes among patients with acute coronary syndromes. Am J Cardiol 2005; 96: $1200-1206$.

51. Eikelboom JW, Mehta SR, Anand SS, Xie C, Fox KA, Yusuf S. Adverse impact of bleeding on prognosis in patients with acute coronary syndromes. Circulation 2006; 114: 774-782.

52. Manoukian SV, Feit F, Mehran R, Voeltz MD, Ebrahimi R, Hamon $\mathrm{M}$, et al. Impact of major bleeding on 30-day mortality and clinical outcomes in patients with acute coronary syndromes: An analysis from the ACUITY Trial. J Am Coll Cardiol 2007; 49: 1362-1368.

53. Stangier J, Rathgen K, Stähle H, Mazur D. Influence of renal impairment on the pharmacokinetics and pharmacodynamics of oral dabigatran etexilate: An open-label, parallel-group, single-centre study. Clin Pharmacokinet 2010; 49: 259-268.

54. Benz K, Nauck MA, Böhler J, Fischer KG. Hemofiltration of recombinant hirudin by different hemodialyzer membranes: Implications for clinical use. Clin J Am Soc Nephrol 2007; 2: 470-476.

55. Sartori MT, Imbergamo S, Zanon E, Bonaccorso G, Pittoni G, Feltracco P, et al. Effect of recombinant activated factor VII in critical bleeding: Clinical experience of a single center. Clin Appl Thromb Hemost 2009; 15: 628-635.

56. Leissinger CA, Blatt PM, Hoots WK, Ewenstein B. Role of prothrombin complex concentrates in reversing warfarin anticoagulation: A review of the literature. Am J Hematol 2008; 83: 137-143.

57. Fernlöf G, Sjöström BM, Lindell KM, Wall UE. Management of major bleedings during anticoagulant treatment with the oral direct thrombin inhibitor ximelagatran or warfarin. Blood Coagul Fibrinolysis 2009; 20: 667-674.

58. Crowther MA, Warkentin TE. Managing bleeding in anticoagulated patients with a focus on novel therapeutic agents. J Thromb Haemost 2009; 7(Suppl 1): 107-110.

59. Baker WL, Cios DA, Sander SD, Coleman CI. Meta-analysis to assess the quality of warfarin control in atrial fibrillation patients in the United States. J Manag Care Pharm 2009; 15: 244-252. 